\title{
Morphological variability of the cranium of Lontra longicaudis (Carnivora: Mustelidae): a morphometric and geographic analysis
}

\author{
Pablo César Hernández-Romero ${ }^{1 *}$, José Antonio Guerrero² and Carolina Valdespino ${ }^{1}$
}

\begin{abstract}
Background: Studies of morphometric variation make it possible to delimit species and geographic intraspecific variation, mainly in species with wide distribution ranges. In the Neotropical otter, Lontra longicaudis, variation in the shape of the rhinarium of three potential subspecies has been described but it is not known whether there is a pattern to the morphometric variation in the skull throughout the distribution of this species. We analyzed morphological variation in the cranium (ventral view) and the mandible (lateral view) of the Neotropical otter, comparing male and female specimens and evaluating the differences between specified geographic units utilizing methods from geometric morphometrics. Specimens from the entire distribution of the species were analyzed. Between sexes, variability in the shape was determined by calculating the Procrustes distances and using Goodall's F test. Geographic variation was analyzed using a discriminant analysis, an analysis of variance (ANOVA) on a matrix of partial warp scores, and a cluster analysis with Mahalanobis distances, allowing for similarities in shape to be identified between different geographic units. Variation in the size of the two structures was calculated based on the values for centroid size using a one-way ANOVA with a Bonferroni correction and a $95 \%$ confidence interval.
\end{abstract}

Results: There was sexual dimorphism in shape for both views, with males the largest. In general, there was geographic variation in the shape and size of both the cranium and the mandible in the Neotropical otter, exhibiting a pattern that resembled Bergmann's rule. Variation in shape between geographic units could result from the presence of geographic barriers, the spatial configuration of hydrological regions, and/or the large distances between populations throughout this species' distribution.

Conclusions: The Neotropical otter exhibits dimorphism in the size, but not in the shape of the skull. There is geographic variation between geographic units, and our results suggest that $L$. longicaudis could be a group of species. An integrative study using molecular and morphological data could elucidate its taxonomy.

Keywords: Geographic variation; Geometric morphometrics; Lontra longicaudis; Sexual dimorphism

\section{Background}

The Neotropical otter (Lontra longicaudis) is an aquatic species with a wide distribution that is limited to the terrestrial-aquatic ecotone that corresponds to lagoon and riparian systems (Gallo-Reynoso et al. 2008). This species is Neotropical in origin and has a continuous distribution from Argentina in South America to the Trans-Mexican Volcanic Belt (Fig. 1). The latter is a mountain range that divides the country in two, follows

\footnotetext{
* Correspondence: pabloecologico@yahoo.com.mx

${ }^{1}$ Instituto de Ecología A.C., Red de Biología y Conservación de Vertebrados, CP 91070, Carretera antigua a Coatepec 351, Xalapa, Mexico

Full list of author information is available at the end of the article
}

the outline of both the Atlantic and Pacific slopes, and ultimately reaches its northern extreme in the state of Sonora on the Pacific slope with its other extreme in Tamaulipas on the Gulf of Mexico slope (Gallo-Reynoso 1997). Sexual dimorphism has been reported for L. longicaudis, with males larger than females (Kruuk 2006). Along its distribution, this otter occupies habitats such as coastal lagoons, rivers, and lakes that are located in distinct geographic and climatic regions, from arid zones to wetlands and from tropical to temperate forests (Larivière 1999). The composition of its diet is also variable between regions 


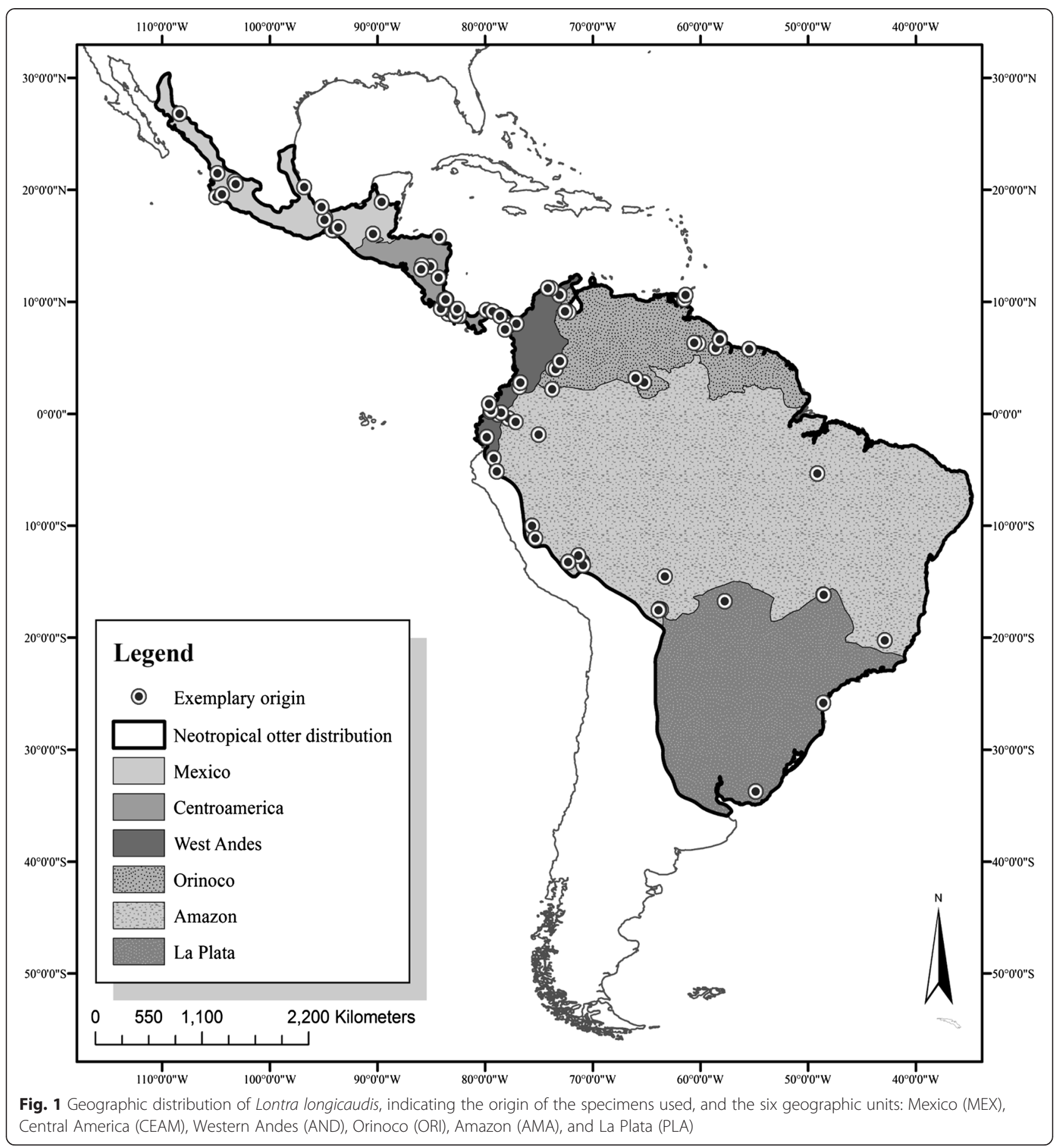

and seasons, though different studies have shown its diet is largely made up of fish and crustaceans and to a lesser extent amphibians, mammals, birds, and turtles (GalloReynoso et al. 2008; Carvalho-Junior et al. 2010; Chemes et al. 2010; Platt and Rainwater 2011). Owing to these factors and the variation in its habitat in terms of vegetation, climate, and food availability throughout its extensive distribution, potential changes in the cranial morphology of $L$. longicaudis may be interpreted as local adaptations to environmental variables such as different types of prey.

The wide geographic distribution of L. longicaudis and the variation in its aquatic habitats give rise to two hypotheses of morphological variation. The first hypothesis is that there should be a differentiation in the shape and size of the cranium and mandible between the sexes, and the second is that these variables differ between 
populations of the different geographic regions throughout its distribution.

In order to test these hypotheses, we used techniques based on geometric morphometrics (Kendall 1984; Bookstein 1991; Lawing and Polly 2010) which describe and interpret changes in the shape of different anatomical structures of organisms, based on comparisons of homologous structures (Adams et al. 2004). This analysis of anatomical shape allows for a better understanding of morphological evolution and adaptive effects (Zelditch et al. 2004) since variation in shape is influenced by environmental factors (Rohlf and Marcus 1993).

Morphometric analysis of the cranium of several species has indicated that patterns of morphological variation in species with large distribution areas might be adaptations to the range of environmental conditions occurring throughout their distribution (Zelditch et al. 2004; Cardini et al. 2007). This pattern has been observed in mammals such as the puma (Puma concolor), the tiger (Panthera tigris), and the brown bear (Ursus arctos), for which variation in the size and configuration of the cranium are correlated with the different geographic regions throughout which their populations are distributed (Gay and Best 1996; Baryshnikov and Puzachenko 2011; Mazák 2011). These patterns of morphological variation are associated with habitat variables such as temperature, precipitation, and latitude (Platz et al. 2011). Patterns of change in the mandible associated with contrasting habitats have been observed in several species of rodents (Duarte et al. 2000). This also occurs for species like the titus monkey, genus Leontopithecus (Freitas et al. 1999), and for bats of the genus Monophyllus (Mancina et al. 2010). And for the green monkey, Cercopithecus aethiops, there is a close relationship between rainfall pattern and the length of its face (clinal variation) (Cardini et al. 2007).

Patterns of morphological change associated with geographic regions are even more notable in species with a high level of habitat specialization, such as aquatic species (Langerhans et al. 2003; Jonsson and Jonsson 2001). For the cichlid Biotodoma wavrini and the characid Bryconops caudomaculatus, distinct morphological adaptations have been found for their two contrasting habitats, river channels and lagoons, where morphological variation increases with increasing geographic distance between populations and with variation in other environmental factors (Langerhans et al. 2003).

Morphological variation in the Eurasian otter (Lutra lutra) has only been assessed using linear morphometric analysis. For example, Ruiz-Olmo et al. (1998) reported that the age of L. lutra may be determined on the basis of its cranial morphology. And variation in cranium size has also been found over the range of this species, with more variability in animals in the tropics (Baryshnikov and
Puzachenko 2012). This technique demonstrated that there is a significant difference in cranial morphology between healthy populations of otters and populations considered at risk due to decreased population size and habitat quality (Pertoldi et al. 2000). In addition, these studies have made it possible to explore any effects of contaminants on the morphology and ontogenesis of the cranium of L. lutra (Pertoldi et al. 1998) and other species such as Ursus maritimus (Pertoldi et al. 2012).

Several taxonomic studies of $L$. longicaudis have postulated that it is potentially composed of a number of species based primarily on the differentiation of its rhinarium (Pohle 1920; Cabrera 1957; Harris 1968). The most recent studies have suggested that populations with distinct rhinarium morphology may be conspecific and that these populations may be subdivided geographically into three subspecies: (I) L. longicaudis annectens, found from Mexico to Colombia and Ecuador; (II) L. longicaudis enudris, distributed in French Guiana, Suriname, Peru, and Trinidad and Tobago; and (III) L. longicaudis longicaudis, distributed throughout most of South America from Brazil to Uruguay and Argentina (Van Zyll 1972; Larivière 1999). However, this classification has also been questioned recently by Trinca et al. (2012) as a result of new insights into the phylogenetic structure of the South American populations based on mitochondrial sequence analysis. These authors mentioned that an intraspecific subdivision continues to be controversial due to genetic differentiation within the different geographic regions, and indicated that an integrative study would be necessary to examine morphological variation in the species, including an analysis of cranial morphometrics.

The present study has the objectives of evaluating changes in the morphology of the cranium and mandible of L. longicaudis using geometric morphometric techniques and examining the variation in the configuration (shape and size) of the cranium and the mandible between sexes and among the different geographic regions of its distribution. Morphological variation associated with distinct geographic regions throughout which the otter is distributed would support previously reported genetic differences.

\section{Methods \\ Sampling}

The crania of 151 specimens of $L$. longicaudis from localities throughout its distribution were examined (Fig. 1). The specimens were housed in the National Collection of Mammals of the National Autonomous University of Mexico, the Mammal Collection of the Autonomous University of Campeche, the Vertebrate Collection of the Biological Station of the National Autonomous University of Mexico in Los Tuxtlas, the Mammal Collection of the University of Kansas, the American Museum of Natural 
History, the Mammal Collection of the Field Museum, the National Museum of Natural History of the Smithsonian Institute, the Carnegie Museum, and the Michigan University Museum (see list of specimens in Additional file 1). Since the Neotropical otter is a threatened species and protected in the majority of the countries where it is found, the analysis was limited to cranium samples from the aforementioned collections.

Each specimen was assigned to one of the three age categories using the criteria of Van Zyll (1972): juvenile (presence of deciduous teeth), subadult (a full set of fully erupted teeth, presence of nasal sutures, and occipitalparietal sutures), and adult (absence of maxillary-nasal and occipital-parietal sutures). For the morphometric analysis, only adult samples were used to avoid the errors associated with the modifications that the cranium undergoes when the animal is growing (Caumul and Polly 2005).

The samples were grouped a priori into six geographic units (GUs): Mexico, Central America, Western Andes, Orinoco, Amazon, and La Plata (Fig. 1) based on the main hydrological delimitations throughout this otter's distribution and on patterns of morphological and genetic structure observed among the different populations of other aquatic species in South America (BangueraHinestroza et al. 2002; Hubert and Renno 2006; Arzamendia and Giraudo 2009), including the Neotropical otter (Trinca et al. 2012).

\section{Digitization of images, recording landmarks, and semi- landmarks}

The analysis of variation in cranial morphology was based on digital images of the cranium in ventral view $(n=64)$ and the mandible in lateral view $(n=87)$. All photographs were taken by the same person to avoid any variation associated with possible different points of view of observers. Specimen placement was standardized, and the crania were photographed on the right side of the face, from a distance of $40 \mathrm{~cm}$ from the camera lens and oriented at an angle of $90^{\circ}$. All images were captured using a Sony Alpha 200 reflex camera with a resolution of $3872 \times 2592$ pixels. A ruler was included in each photograph as a reference scale.

The use of only the right side of the cranium and the mandible to locate the landmarks assumes bilateral symmetry in these structures. The configuration of the cranium and the mandible was recorded using landmarks (LMs), which are natural points located on homologous sites and that can be easily located on any specimen (Bookstein 1997), and semi-landmarks (SLMs), which are located along the homologous outlines of the structures and are based on templates drawn between the LM points (Bookstein 1991; Gunz and Mitteroecker 2013). Outlines were drawn using
MakeFan6 software (Sheets 2003) to facilitate the location of the SLMs and were based on two LMs (numbers 1 and 8 for the mandible and 1 and 16 for the cranium, Fig. 2). LMs and SLMs were digitized for each specimen using the TpsDig 2.15 software (Rohlf 2001), and configuration matrices obtained for each view. For these matrices, a generalized Procrustes superposition adjustment (Rohlf and Slice 1990) was applied using the software CoorGen6f (Sheets 2005a), where variation associated with the effects of positioning, orientation, and scale is minimized by calculating the sum of the squared differences between corresponding landmarks (Bookstein 1991; Zelditch et al. 2004). The placement of the outlines for the positioning of the SLMs results in a shape distortion during the Procrustes adjustment (Bookstein 1996; Gunz and Mitteroecker 2013), so a second adjustment was made to eliminate variation by sliding the SLMs based on the alignment distance criteria of the Semiland software (Sheets 2002).

For each configuration of LMs and SLMs (2 LMs and 21 SLMs on the ventral cranium view; 2 LMs and 16 SMLs on the lateral mandible view), an eigen analysis was done following the methodology of Bookstein (1991) and Rohlf (1996). This analysis allows a tangent space to be converted to a Euclidian space, making it possible to use conventional multivariate statistical analyses (Rohlf 1996). The average general shape was used as a reference, and each sample was described in terms of its deviation from the average form for all specimens. The resulting matrices describe change in shape (partial warp scores, PWS) and size as measured from the centroid size (CS). These variables were used in subsequent analyses to describe the change in shape and size of the skull and mandible.

\section{Statistical analysis}

A two-way analysis of variance (ANOVA) for centroid size and a two-way multivariate analysis of variance (MANOVA) for shape were performed to test a priori the differences between sexes and among GUs. Specimens from La Plata were excluded from both analyses of the ventral view because only females were available for this GU. These analyses were run using Statistica 8.0 software (StatSoft 2007).

\section{Sexual dimorphism in shape and size}

Because sexual dimorphism has been reported for several species of otter (Kruuk 2006), we analyzed shape and size differences between sexes, based on 70 mandible images (36 male and 34 female) and 56 cranium images (29 male and 27 female). To this end, a principal component analysis (PCA) and two-way MANOVA were run to test for sexual dimorphism in the shape of the mandible and the cranium. Subsequently, a 

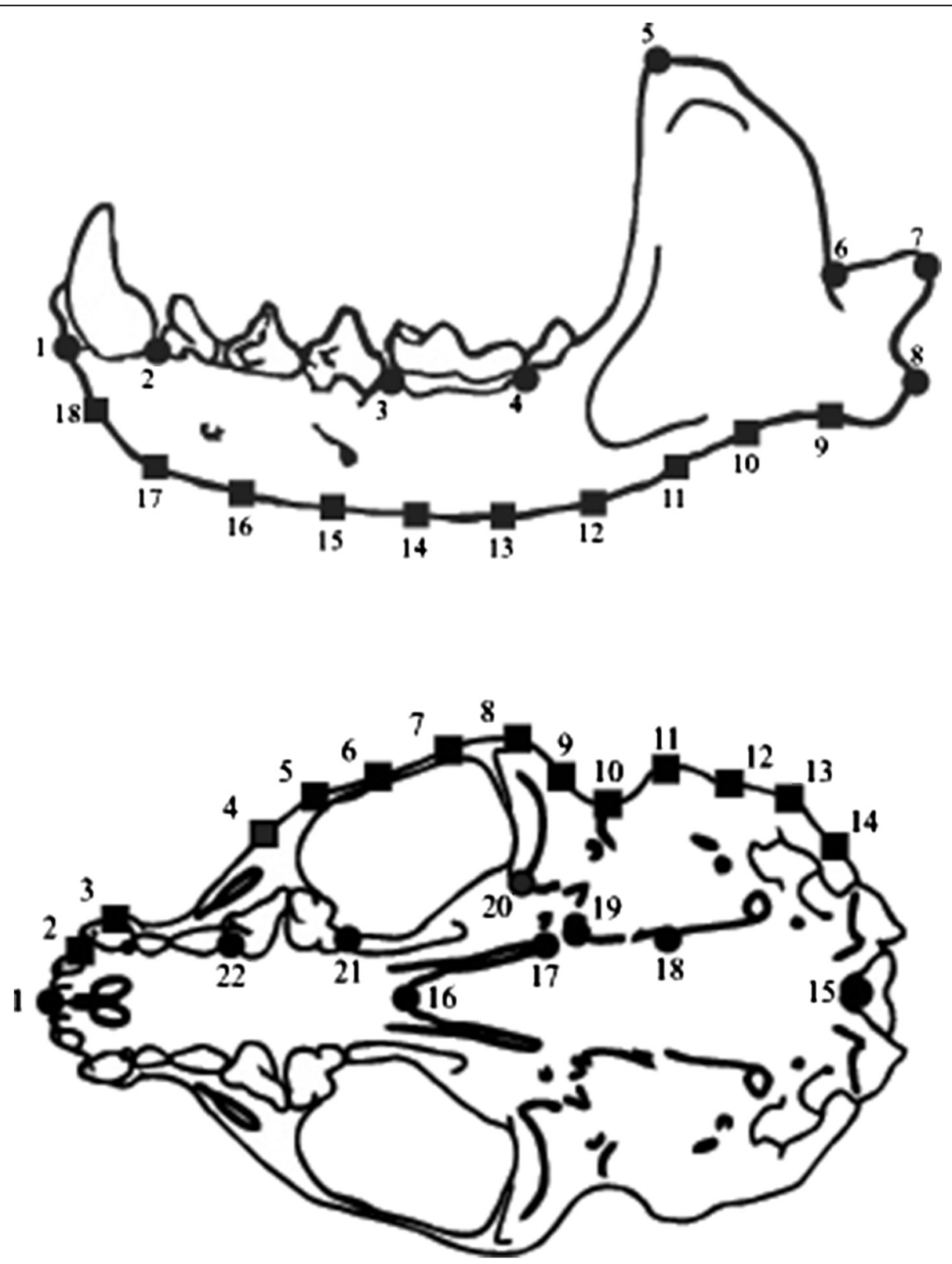

Fig. 2 Landmarks used to capture the configuration of the mandible $(L M=8$ and $S L M=10)$ and the ventral view of the cranium (LM=9 and $\mathrm{SLM}=14$ ) of Lontra longicaudis. Circles are LM and squares SLM

permutation test was performed using Goodall's $F$ test, designed to compare Procrustes coordinates (Goodall 1991, Zelditch et al. 2004), as implemented in the software TwoGroup6 (IMP series; Sheets and Zeldich 2001). The significance of the differences was tested with 2500 bootstrap permutations. The variation in size between the sexes was analyzed using an ANOVA with Bonferroni correction and a $95 \%$ confidence interval and run in Statistica 8.0 (StatSoft 2007). These analyses were run to determine whether the data for males and females could be pooled for subsequent tests.

\section{Geographic variation in shape and size}

Due to the low number of specimens used for the analysis of geographic variation and the fact that no significant sexual dimorphism was found for either structures (see "Results"), the data for both sexes were combined to analyze for geographic variation. 
Canonical variables were extracted in a multidimensional space in order to explain the majority of the variation between groups for which the partial warp scores matrix was used. To assess shape variation between GUs in both views, a canonical variate analysis (CVA) was run in CVAGen6 software (Sheets 2005b). We obtained thin-plate spline plots (deformation grids describing shape changes) by regressing the PWS onto the first and second canonical variables. Subsequently, a discriminant function analysis (DFA) using Mahalanobis distances was calculated to assess the validity of the a priori classification of the specimens into six GUs.

Applying a MANOVA, a significant difference in shape was detected between the distinct GUs. To describe morphological similarity between GUs, a cluster analysis with the Unweighted Pair Group Method with Arithmetic Mean (UPGMA) was used, using the Mahalanobis distance between GUs. The DFA and UPGMA were run in Statistica 8.0 (StatSoft 2007).

Variation in cranium and mandible size between the six GUs of $L$. longicaudis was analyzed using a one-way ANOVA, with log-natural-transformed values of centroid size. Post hoc comparisons among GUs were run using a Bonferroni correction and a $95 \%$ confidence interval in Statistica 8.0 (StatSoft 2007).

\section{Results}

\section{Sexual dimorphism in shape and size}

The PCA of the skull and the mandible indicate a small proportion of the variance was explained by the first two principal components, 63.6 and $42.9 \%$, respectively. Plots of these two components for each structure showed continuous variation between male and females, indicating the absence of sexual dimorphism (Fig. 3). This was confirmed by Goodall's $F$ tests which showed that there were no significant differences in the shape of either structure between sexes (mandible: Goodall's $F_{(32)}=0.75$, $p=0.84224$; skull: Goodall's $\left.F_{(42)}=1.62, p=0.1271\right)$. Hence, we pooled female and male samples in subsequent analyses. The results of the ANOVA for centroid size indicated that males are significantly different from females in both skull size $\left(F_{(1,54)}=6.2030, p=0.0158\right)$ and mandible size $\left(F_{(1,68)}=9.8040, p=0.0025\right)$, with males larger (median CS mandible $=103.76$, median CS skull $=169.76$ ) than females (median CS mandible $=95.76$, median CS skull $=161.53)$ for both views.

\section{Geographic variation in the shape of the mandible and the cranium}

The MANOVA detected significant differences in skull (Wilks' $\lambda=0.014, F=1.362, p<0.05$ ) and mandible (Wilks' $\lambda=0.013, F=1.606, p<0.001)$ shapes between GUs. The CVA plots depict the patterns of change between the GUs defined in this study for both structures (Fig. 4). For both views, the samples from La Plata differed the most from the samples from the other GUs. The shape of the cranium had the most marked differences between GUs. For the change in the deformation axes of the mandible between GUs, the $\mathrm{VC} 1$ values indicate a change in the height of the coronoid process, which includes the emergence of the first and second molars, and in the width of the set of teeth. For the second canonical correlation (VC2), a change in shape was found between landmarks 1 and 8 , which corresponds to the length of the mandible.

The deformation grid of the cranium between the GUs along VC1 (Fig. 5) shows a change in the shape of the posterior neurocranium (LMs 12-14) and the foramen

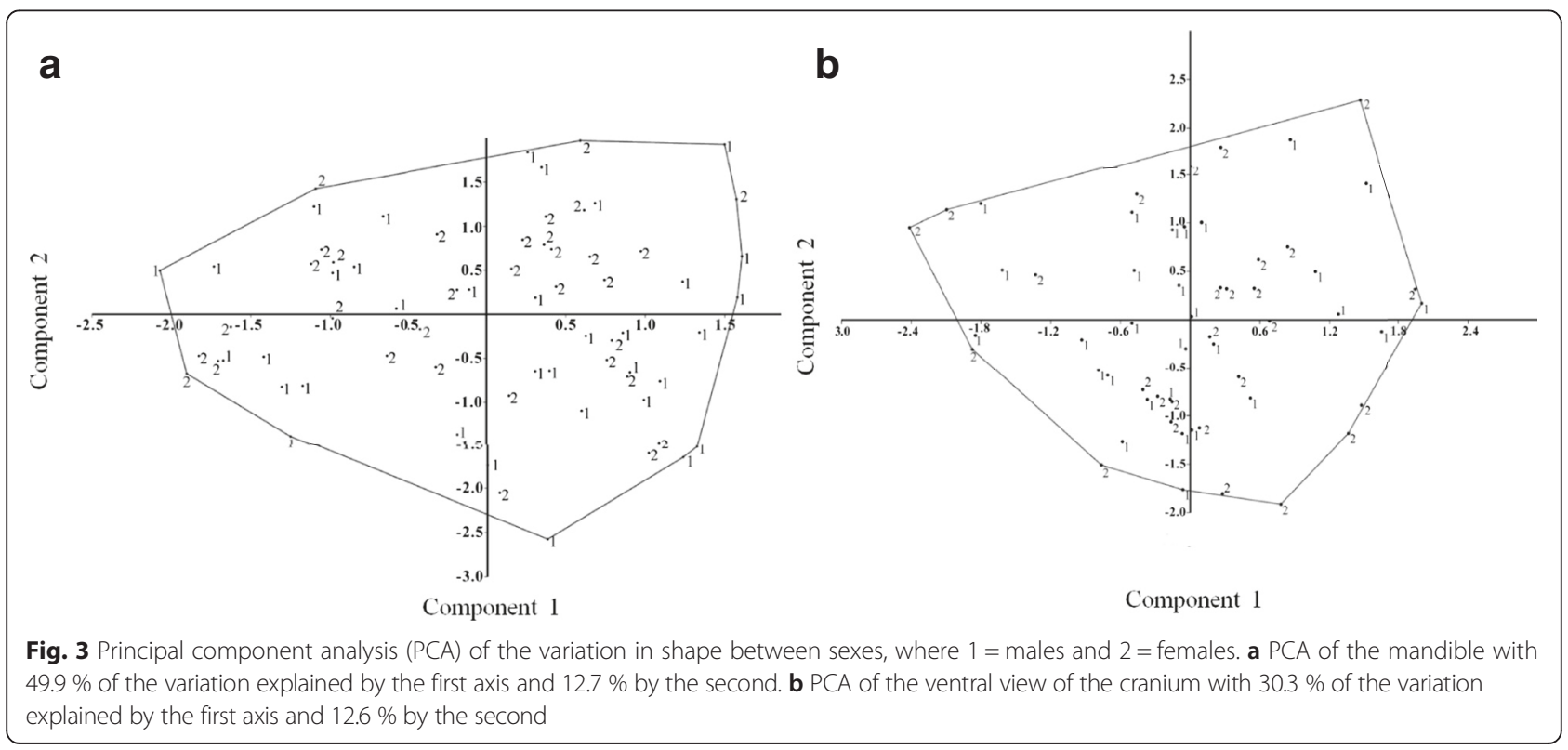




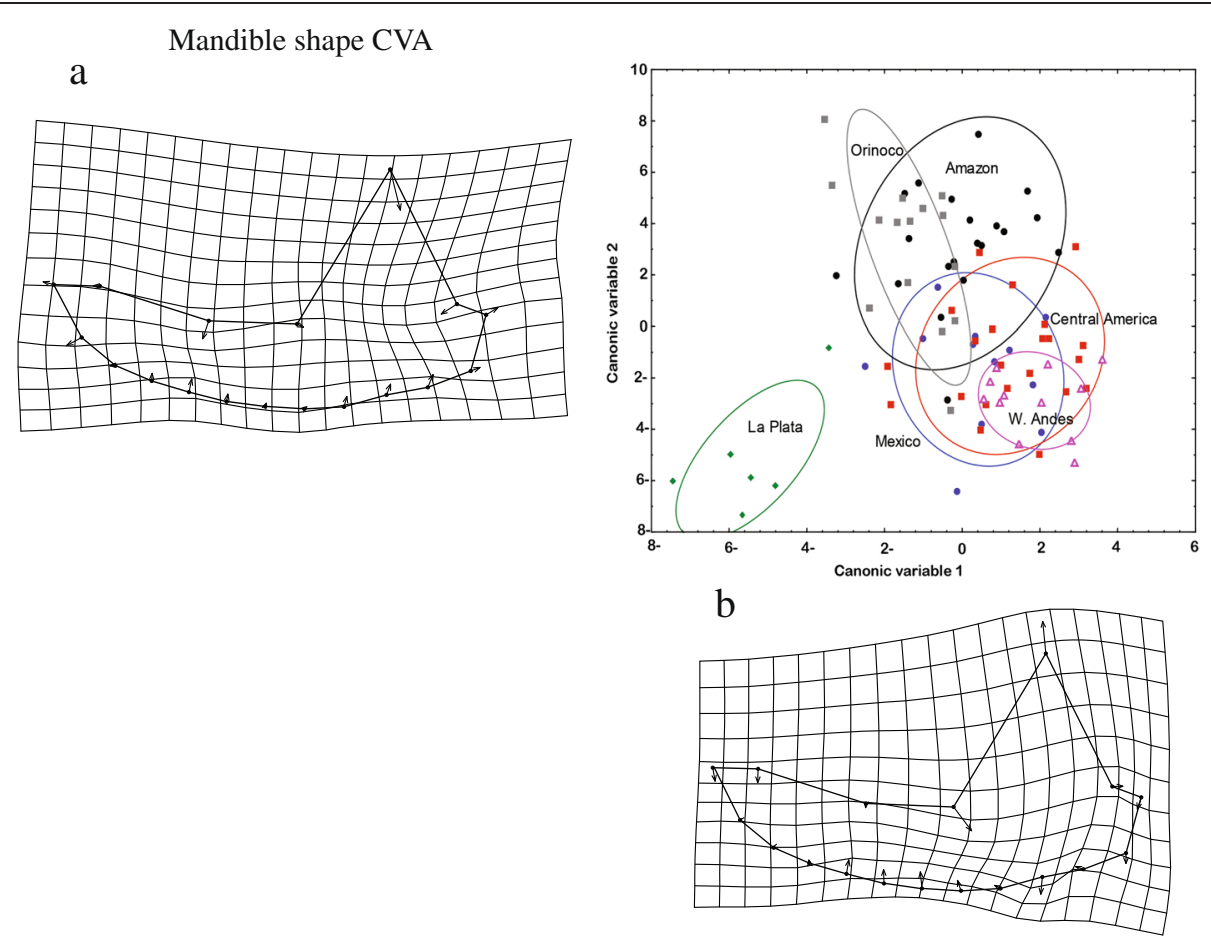

Fig. 4 a, b Analysis of the canonical variables and planes of deformation for the shape of the mandible in lateral view between geographic units. The arrows indicate the direction and magnitude of change

magnum (LM 15), in addition to a decrease in the width of the zygomatic arch. For VC2, there is an increase in the length of the mastoid bone (LM 11), along with an increase in the distance between the pterygoid muscles (LM 17) and a decrease in the distance between the rows of molars and premolars (LMs 21 and 22). The DFA of the mandible demonstrated that the a priori grouping of the specimens in six GUs is appropriate, with the majority of mandible samples correctly assigned $(89.6 \%)$ (Fig. 6). The analysis of the mandible for

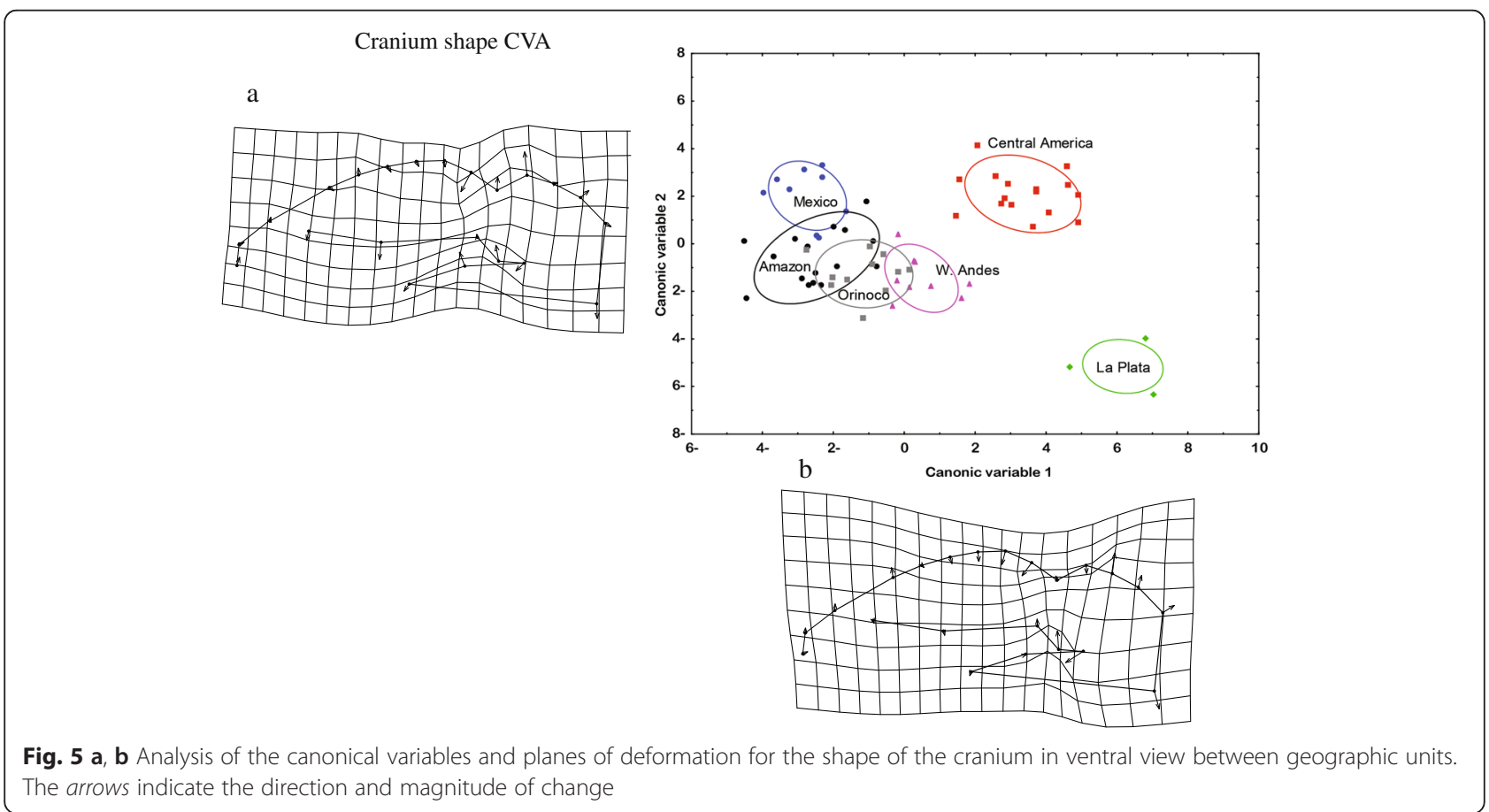


specimens from the six GUs using the Mahalanobis distances resulted in three groups. The first group is formed by the Amazon region, the Western Andes, Central America, and Mexico, Mexico being the region with the most differences within this grouping. The second group has the specimens from the Orinoco, and the third group is formed by the specimens from La Plata, the region with the lowest level of similarity with respect to the other GUs (Fig. 6).

The deformation grid of the cranium between the GUs along $\mathrm{VC1}$ (Fig. 5) shows a change in the shape of the posterior neurocranium (LMs 12-14) and the foramen magnum (LM 15), in addition to a decrease in the width of the zygomatic arch. For VC2, there is an increase in the length of the mastoid bone (LM 11), along with an increase in the distance between the pterygoid muscles (LM 17) and a decrease in the distance between the rows of molars and premolars (LMs 21 and 22).

The DFA of the cranium samples indicated that $98.43 \%$ were correctly assigned to the GUs by the discriminant analysis (Fig. 6). The analysis of the grouping of the six GUs using the Mahalanobis distances shows that the variation in shape of the mandible of $L$. longicaudis allowed the specimens to be classified into three groups. The first group includes specimens from the Amazon, Orinoco, and Mexico, Mexico being the unit with the most differences in shape within this larger grouping. The second most different group is that of the Western Andes and Central America. The third group has the samples from La Plata, the region with the lowest similarity with respect to the other GUs (Fig. 6).

\section{Geographic variation in size}

Differences were found $\left(F_{(5,81)}=3.9603, p=0.0029\right)$ in the size of the mandible between the specimens from distinct
GUs. The multiple comparison test with a Bonferroni correction classified the GUs into three groups. The first group included Western Andes, the Amazon, and Central America (average centroid size 107.27); the second Orinoco and La Plata (average centroid size 112.28), and the third Mexico (average centroid size 122.59). There were marginally significant differences in size of the cranium $\left(F_{(5,58)}=2.3123, p=0.0553\right)$ between the GUs.

\section{Discussion}

\section{Sexual dimorphism in shape and size}

This is the first study to use geometric morphometric techniques to describe the sexual and geographic variations in the cranium and mandible of $L$. longicaudis throughout its distribution. The results indicate that there is no sexual dimorphism in the shape of the mandible or the skull of the Neotropical otter, though both structures do differ in size. This difference corresponds to a pattern of sexual dimorphism common in the Mustelidae family where males are generally larger than females (Moors 1980). The Eurasian otter L. lutra (Lynch and O'Sullivan 1993; Lynch et al. 1996; Baryshnikov and Puzachenko 2012) and the river otter Lontra canadensis (Pertoldi et al. 2000; Kruuk 2006) also have this pattern. Given that the difference in the size of the cranium and the mandible of the otters is correlated with body size (Pertoldi et al. 1998), the difference in size between sexes of $L$. longicaudis could be associated with its characteristically solitary habit and territorial behavior. The males of L. lutra must defend their territory, and a larger body ensures a higher position in the hierarchy and potentially better territory (Pertoldi et al. 1997; Kruuk 2006). For L. canadensis, social behavior has been reported and there are even cases of overlapping territories between males (Blundell et al. 2002; Melquist et al. 2003), though the territories of the males are larger
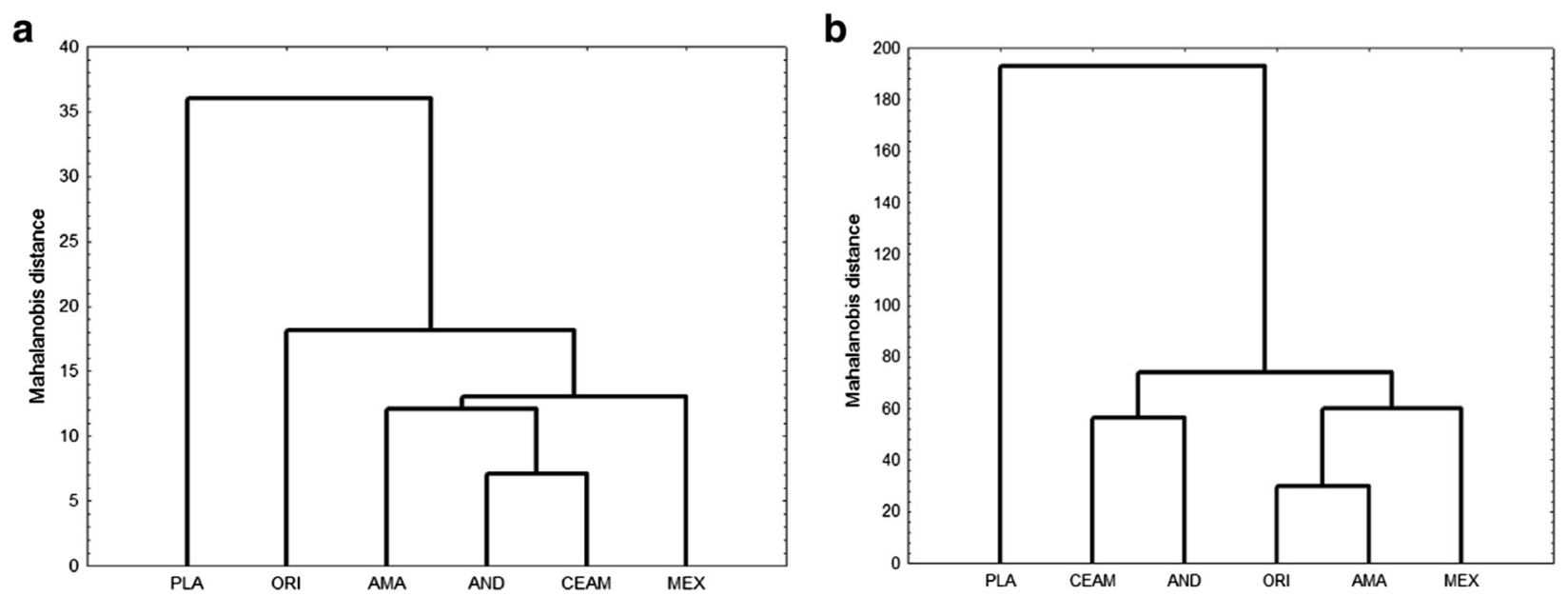

Fig. 6 UPGMA dendrogram of geographic samples based on the Mahalanobis distances matrix for the a mandible and $\mathbf{b}$ cranium. MEX Mexico, CEAM Central America, PLA La Plata, AND Western Andes, AMA Amazon, and ORI Orinoco 
in size than those of the females possibly due to the larger energetic requirement of having a larger body (Sandell 1996; Thom et al. 2004). On the other hand, females do not engage in territorial disputes and are smaller, with lower energy requirements for daily maintenance. It is thought that the excess of energy is allocated to raising the litters (Moors 1980; Pertoldi et al. 1997; Gorman et al. 2006).

\section{Geographic variation in the size and shape of the skull and mandible}

The size of the mandible differs between GUs: animals from Mexico and La Plata have larger mandibles relative to those from the other GUs. These two GUs are the most northern (Mexico) and southern (La Plata) distributions of $L$. longicaudis. This variation is congruent with the size patterns reported for other species, like the American puma, $P$. concolor, which in addition to having a large distribution, like the Neotropical otter, also has a larger cranium size in temperate regions and with increasing latitudinal distance from the Equator (Iriarte et al. 1990; Gay and Best 1996). These patterns of change correspond to Bergmann's rule, which dictates that populations located furthest from the Equator have a relatively larger body. It is assumed that this pattern is the result of an adaptation that allows the animal to maintain its body temperature and confers greater endurance during aestivation (Blackburn and Hawkins 2004).

Cranium size does not follow the pattern observed for the mandible: the specimens from Mexico had a larger centroid size, while for the specimens from La Plata, it was smaller. In this study, only four samples were used from the La Plata region, so it is necessary to increase the sample size to determine whether this pattern would still be observed.

Our results indicated that significant variation in the shape of the cranium and the mandible of the Neotropical otter is associated with geography. In other species of Mustelidae such as weasels, European minks, and European badgers (Lee and Mill 2004), it is assumed that this type of variation responds to the variation in environmental conditions throughout the distribution of the species (Kruuk 2006). The morphology of a species responds to select factors in the environment, in addition to limitations in the response of the phenotype to such factors. This has led to the proposal that the ecological and geographic distribution of populations is a reflection of the ecological range of a phenotype (Ricklefs and Miles 1994). In contrast, it has been reported that geographic differences do not always lead to a homologous effect on the shape and size of an anatomical structure, in this case the cranium, due to the high levels of plasticity and adaptation in size that have been observed in other mammals (Cardini et al. 2007). Our data indicates that for L. longicaudis, there are changes in shape as well as size between the GUs studied, suggesting the existence of different selective pressures to which the shape and size of the cranium and the mandible respond and different means of adaptation.

In general, variation in shape corresponded to an increase in distance between the GUs. For example, the shortest Mahalanobis distances were between the Orinoco and the Amazon for the cranium and between Central America and the Western Andes for the mandible. In both cases, the GUs are adjacent hydrological regions and the proximity of the regions could allow for regional migration. The similarity between neighboring hydrological regions is exemplified by the genetic distance between the giant otter populations of Pteronura brasiliensis, located in the Amazon Basin, the Orinoco, and Guyana, suggesting that these populations originated from an ancestral population that inhabited the central region of the Amazon. Several populations of giant otter subsequently diverged and were partially isolated, although similarity may have been maintained between them by gene flow (Pickles et al. 2011). Likewise, for those GUs that are geographically most distant, such as Mexico and La Plata, greater Mahalanobis distances were also found for both structures. To elaborate, it was expected that these two regions would have the greatest differences in shape for the two views: not only due to geographic distance but also because these GUs are located at the limits of the Neotropical otter's distribution. Organisms that live at the limits of their distribution generally exhibit the greatest morphological change, as they are generally subject to suboptimal conditions that may challenge their limits of tolerance (Gay and Best 1996).

Morphological variation is not always associated with geographic distance, as in some cases it may be explained by the presence of different evolutionary units that are delimited by geographic barriers that successively give origin to vicariance events (Patton and Smith 1994; De Queiroz and Good 1997; Smith et al. 1997). This pattern is observed in the GUs of the Western Andes, for which there was less variation in shape compared with Central America than with the adjacent regions of the Orinoco and the Amazon. The Andes mountain range is a potential geographic barrier that may give rise to vicariance events.

The hypothesis of vicariance events caused by the Andes supports the genetic distances reported by Trinca et al. (2012), who found large genetic distances between the phylogenetic groups of South America and those of the Western Andes, where genetic distances are greater between populations of $L$. longicaudis than with its sister species, Lontra provocax. This separation also corresponds to a subspecies division: $L$. longicaudis annectens is distributed throughout the Western Andes and L. longicaudis enudris 
is distributed throughout the Eastern Andes (Larivière 1999). The effect of population separation by the Andes mountain range has also been reported for other vertebrate species including some South American fish (Hubert et al. 2007) and bats belonging to the genus Artibeus (Larsen et al. 2007), where the elevation of the Andes prevents gene flow and has resulted in different species on each side of the mountain range. The results of the present study offer morphological information that concurs with the molecular data from Trinca et al. (2012) on the separation of populations of the Eastern and Western Andes. This indicates that sufficient time has passed for both the morphological and the genetic divergence of the populations of L. longicaudis on both sides of the mountain range.

Another important pattern that reinforces the possibility of divergence events for the Neotropical otter was the notable differentiation in the shape of the mandible and cranium of the animals from La Plata with respect to those from the other five GUs. This reinforces the possibility of divergence events for the Neotropical otter. This dissimilarity for La Plata corresponds to the geographic group labeled Eastern South America and reported by Trinca et al. (2012), which was formed by a clade that does not share a single haplotype with the other clades that were reported on by the authors. This pattern of differentiation corresponds to the genetic variation between the populations of Pantanal, which belongs to the hydrological region of La Plata, and the other populations of the giant otter P. brasiliensis (Pickles et al. 2011).

In addition, this pattern of differentiation in shape may be influenced by the two biogeographically distinct regions in the La Plata Basin-tropical in the north and subtropical-temperate in the south-where climatic zoning has promoted changes in distribution and diversification patterns in both aquatic and terrestrial (Arzamendia and Giraudo 2009) species, and has possibly had the same effect on the Neotropical otter. Added to this effect is the presence of prairies that may be functioning as a barrier between the Amazon and La Plata during the dry season when bodies of water become scarce, preventing the Neotropical otter from migrating from one hydrological region to another.

Finally, it is important to address the pattern found for the Mahalanobis distance values and for the UPGMA, and the variation in the shape of the mandible and the cranium for specimens found in Mexico. These specimens showed no association with any of the other GUs, thereby indicating that the otters of this region could be under selective forces that are allowing for this differentiation. A similar pattern occurred in the morphology of the cranium of Panthera onca (Larson 1997), confirmed by molecular analysis (Eizirik et al. 2001), for which there is also a pattern of geographic division for populations in Mexico and Central America in comparison to the populations of South America. This pattern has also been found for the ocelot, Leopardus pardalis, and the margay, Leopardus wiedii, using molecular data (Eizirik et al. 1998), species which both have distributions similar to that of the Neotropical otter.

This supports the idea that the otters in Mexico and Central America have been separated from the more southern populations and are subject to a distinct set of selective pressures, resulting in important morphological variations that are reflected in the shape and size of the cranium and the mandible. On the other hand, since the Pacific and Gulf of Mexico slopes where L. longicaudis is distributed are separated by the Central Mexican Plateau, it is possible that the shape and size of the cranium also vary between the two coastlines. We recommend that a morphometric study be undertaken to compare populations from the two regions separated by the Trans-Mexican Volcanic Belt that bifurcates and creates the Pacific and the Atlantic ridge. This would allow for a better description of any vicariance event that has happened between these hydrological regions of Mexico.

The hypothesis that $L$. longicaudis is a species complex is supported by the geographic distances, the presence of geographic barriers, and the morphological adaptations to distinct environmental conditions that exist throughout its distribution, as well as by the congruence between the morphological differences we report here and the genetic information reported in Trinca et al. (2012). This hypothesis should be further tested using an integrative approach that includes phylogeographic information and geometric morphometrics with an appropriate number of sequences and representative sampling for the entire distribution of the Neotropical otter, especially in Mexico and the La Plata region. This would elucidate the current status of $L$. longicaudis as a possible group of species, as proposed by other authors based on the form of the rhinarium (Pohle 1920; Cabrera 1957; Harris 1968). The results of such a study would have important consequences for the knowledge and conservation of this species given that L. longicaudis is on the Red List of Threatened Species of the International Union for Conservation of Nature (IUCN) and is currently categorized as data deficient, due to uncertainty about the rate decline of its populations and debate over its taxonomic status (IUCN 2015).

\section{Conclusions}

The present results add new information about morphometric skull variation in $L$. longicaudis. There is significant variation in the size of the cranium between male and female Neotropical otters, with the males' crania the biggest. In contrast, the variation in shape is not significant between sexes. 
The cranial and mandible shape analysis indicated the morphometric distance was greatest between the La Plata and the other GUs, whereas the smallest distance was found between the Western Andes and Central America for the cranium and Amazonia and Orinoco for the mandible.

For size variation, both views indicated that specimens from Mexico are the biggest relative to the other GUs, in concurrence with Bergmann's rule. The presence of geographic barriers and the large distances between the GUs could have given rise to the morphological variation observed in the Neotropical otter. The results of this study and previous research on genetic variability suggest that $L$. longicaudis could actually be a group of species and therefore requires an integrative study to clarify its taxonomy.

\section{Additional file}

Additional file 1: Additional material: origin of specimens. Examined specimens of Lontra longicaudis for the mandible. National Mammal Collection of the Biological Institute of the Autonomous National University of Mexico (NMC-UNAM), Vertebrate Collection of the Autonomous University of Campeche (VC-AUC), Mammal Collection of the Biological Research Station of Los Tuxtlas, Autonomous National University of Mexico (MCT-UNAM), American Natural History Museum (ANHM), Carnegie Museum of Natural History (CM), Field Museum of Chicago (FIELD), National Museum of Natural History-Smithsonian (SM), Museum of Michigan State University (MSU), Mammal Collection of Kansas University (KU), and private collections (PC).

\section{Competing interests}

The authors declare that they have no competing interests.

\section{Authors' contributions}

PCHR conceived this study and acquired the data. PCHR and JAG coordinated this study and performed data analysis. PCHR, JAG, and CV interpreted the data and drafted and revised the manuscript. All authors read and approved the final manuscript.

\section{Acknowledgements}

This study was started with a Seed Fund Grant awarded by the State University of New York (SUNY) and funding from the Instituto de Ecología A.C. (INECOL). PCHR received a doctoral studies scholarship from CONACYT. Carla Gutierrez and Ella Vázquez contributed to this article with ideas and comments. We thank all the curators for their kindness and permission to use their Lontra longicaudis samples and for access to the following collections: National Collection of Mammals of the National Autonomous University of Mexico, the Mammal Collection of the Autonomous University of Campeche, the Vertebrate Collection of the Biological Station of the National Autonomous University of Mexico in Los Tuxtlas, the Mammal Collection of the University of Kansas, the American Museum of Natural History, the Mammal Collection of the Field Museum, the National Museum of Natural History of the Smithsonian Institute, the Carnegie Museum, and the Michigan University Museum. Bianca Delfosse revised the English.

\section{Author details}

'Instituto de Ecología A.C., Red de Biología y Conservación de Vertebrados, CP 91070, Carretera antigua a Coatepec 351, Xalapa, Mexico. ${ }^{2}$ Facultad de Ciencias Biológicas, Universidad Autónoma del Estado de Morelos, C. P. 62210 Cuernavaca, Morelos, Mexico.

Received: 25 August 2014 Accepted: 8 June 2015

Published online: 26 June 2015

\section{References}

Adams DC, Rohlf FJ, Slice DE (2004) Geometric morphometrics: ten years of progress following the "revolution". Italian J Zool 71:5-16

Arzamendia V, Giraudo AR (2009) Influence of large South American rivers of the Plata Basin on distributional patterns of tropical snakes: a panbiogeographical analysis. J Biogeogr 36:1739-1749

Banguera-Hinestroza E, Cárdenas H, Ruiz-García M, Marmontel M, Gaitán E, Vázquez R, García-Vallejo F (2002) Molecular identification of evolutionarily significant units in the Amazon River dolphin Inia sp. (Cetacea: Iniidae). Journal of Heredity 93:312-322

Baryshnikov GF, Puzachenko AY (2011) Craniometrical variability in the cave bears (Carnivora, Ursidae): multivariate comparative analysis. Quat Int 245:350-368

Baryshnikov GF, Puzachenko AY (2012) Craniometrical variability of the Eurasian otter (Lutra lutra: Carnivora: Mustelidae) from the Northern Eurasia. Zoological Institute Russian Academy of Sciences 316(3):203-222

Blackburn TM, Hawkins BA (2004) Bergmann's rule and the mammal fauna of northern North America. Ecography 27:715-724

Blundell GM, Ben-David M, Bowyer RT (2002) Sociality in river otters: cooperative foraging or reproductive strategies? Behav Ecol 13:134-141

Bookstein EL (1991) Morphometric tools for landmark data: geometry and biology. Cambridge University Press, London

Bookstein EL (1996) Biometrics, biomathematics and the morphometric synthesis. Bull Math Biol 58:313-365

Bookstein EL (1997) Landmark methods for forms without landmarks: morphometrics of group differences in outline shape. Med Image Anal 1:225-243

Cabrera A (1957) Catálogo de los mamíferos de América del Sur. I (MetatheriaUnguiculata-Carnivora). Revista del Museo Argentino de Ciencias Naturales "Bernardino Rivadavia" e Instituto Nacional de Investigación de las Ciencias Naturales. Ciencias Zoológicas 4:1-307

Cardini A, Jansson AU, Elton S (2007) A geometric morphometric approach to the study of ecogeographical and clinal variation in vervet monkeys. J Biogeogr 34:1663-1678

Carvalho-Junior O, Macedo-Soares L, Birolo AB (2010) Annual and interannual food habits variability of a Neotropical otter (Lontra longicaudis) population in Conceicao Lagoon, south of Brazil. IUCN Otter Special Group Bulletin 27(1):1-15

Caumul R, Polly PD (2005) Phylogenetic and environmental components of morphological variation: skull, mandible, and molar shape in marmots (Marmota, Rodentia). Evolution 59:2460-2472

Chemes BS, Graudo RA, Gil G (2010) Dieta de Lontra longicaudis (Carnivora: Mustelidae) en el Parque Nacional El Rey (Salta, Argentina) y su comparación con otras poblaciones de la Cuenca del Paraná. Mastozoología Neotropical 17(1):19-29

De Queiroz K, Good DA (1997) Phenetic clustering in biology: a critique. Q Rev Biol 72:3-30

Duarte LC, Rabello ML, Von Zuben FJ, Furtado DS (2000) Variation in mandible shape in Thrichomys apereoides (Mammalia: Rodentia): geometric analysis of a complex morphological structure. Syst Biol 49(3):563-578

Eizirik E, Bonato SL, Johnson P, Crawshaw PG Jr, Vié JC, Brousset DM et al (1998) Phylogeographic patterns and evolution of the mitochondrial DNA control region in two Neotropical cats (Mammalia, Felidae). J Mol Evol 47:613-624

Eizirik E, Kim J, Menotti-Raymond M, Grawshaw PG Jr, O'Brien SJ, Johnson WE (2001) Phylogeography, population history and conservation genetics of jaguars (Panthera onca, Mammalia, Felidae). Mol Ecol 10(1):67-79

Freitas BCH, M-d L, Pissinatti A (1999) Cranial and mandibular morphometry in Leontopithecus Lesson, 1840 (Callitrichidae, Primates). Am J Primatol 48:185-196

Gallo-Reynoso JP (1997) Situación y distribución de las nutrias en México, en énfasis en Lontra longicaudis annectens MAJOR, 1897. Revista Mexicana de Mastozoologia 2:10-32

Gallo-Reynoso JP, Ramos-Rosas N, Rangel-Aguilar O (2008) Depredación de aves acuáticas por la nutria neotropical (Lontra longicaudis annectens), en el Río Yaqui, Sonora, México. Revista Mexicana de la Biodiversidad 79:275-279

Gay SW, Best TL (1996) Relationships between abiotic variables and geographic variation in skulls of pumas (Puma concolor: Mammalia, Felidae) in North and South America. Zool J Linn Soc 117:259-282

Goodall CR (1991) Procrustes methods in the statistical analysis of shape (with discussion and rejoinder). J R Stat Soc, Ser B 53:285-339

Gorman TA, Erb JD, McMillan BR, Martin DJ (2006) Space use and sociality of river otters (Lontra canadensis) in Minnesota. J Mammal 87(4):740-747

Gunz P, Mitteroecker P (2013) Semilandmarks: a method for quantitative curves and surfaces. Hystrix 24(1):103-109 
Harris CJ (1968) Otters: a study of the recent Lutrinae. Weinfield and Nicholson, London

Hubert N, Renno JF (2006) Historical biogeography of South American freshwater fishes. J Biogeogr 33:1414-1436

Hubert JM, Duponchelle F, Nuñez J, Garcia-Davila C, Paugy D, Renno JF (2007) Phylogeography of the piranha genera Serrasalmus and Pygocentrus: implications for the diversification of the Neotropical ichthyofauna. Mol Ecol 16:2115-2136

Iriarte JA, Franklin WL, Johnson WE, Redford KH (1990) Biogeographic variation of food habits and body size of the America puma. Oecologia 85:185-190

IUCN (2015) The IUCN Red List of Threatened Species. Version 2015.1. $<$ <ww.iucnredlist.org >

Jonsson B, Jonsson N (2001) Polymorphism and speciation in Arctic charr. J Fish Biol 58:605-638

Kendall DG (1984) Shape-manifolds, procrustean metrics, and complex projective spaces. Bull Lond Math Soc 16:81-121

Kruuk H (2006) Otters: ecology, behaviour and conservation. Oxford University Press, Great Britain

Langerhans BR, Layman CA, Langerhans AK, Dewitt TJ (2003) Habitat-associated morphological divergence in two Neotropical fish species. Biol J Linn Soc 80:689-698

Larivière S (1999) Lontra longicaudis, Olfers 1818. Mamm Species 609:1-5

Larsen PA, Hoofer SR, Bozeman MC, Pedersen SC, Genoways HH, Phillips CJ, Pumo DE, Bajer RJ (2007) Phylogenetics and Phylogeography of the Artibeus jamaicensis complex based on Cytochrome-b DNA sequences. J Mammal 88(3):712-727

Larson SE (1997) Taxonomic re-evaluation of the jaguar. Zoo Biol 16:107-120

Lawing AM, Polly PD (2010) Geometric morphometrics: recent applications to the study of evolution and development. J Zool (Lond) 280:1-7

Lee S, Mill PJ (2004) Cranial variation in British mustelids. J Morphol 260:57-64

Lynch JM, O'Sullivan WM (1993) Cranial form and sexual dimorphism in the Irish otter Lutra lutra. Biology and Environment: Proceedings of the Royal Irish Academy 93B:97-105

Lynch JM, Conroy JWH, Kitchener AC, Jefferies DJ, Hayden TJ (1996) Variation in cranial form and sexual dimorphism among five European populations of the otter Lutra lutra. Zoology 238:81-96

Mancina CA, Balsero F (2010) Variación en la forma de la mandíbula en Monophyllus redmani (Chiroptera: Phyllostomidae): análisis geométrico de la variación sexual y geográfica. Mastozoología Neotropical 17(1):87-95

Mazák JH (2011) Craniometric variation in the tiger (Panthera tigris): implications for patterns of diversity, taxonomy and conservation. Mamm biol 75:45-68

Melquist WE, Polechla P Jr, Toweill D (2003) River otter. In: Feldhamer GA, Thompson BC, Chapman JA (eds) Wild mammals of North America: biology, management and conservation, 2nd edn. Johns Hopkins University Press, Baltimore, pp 708-734

Moors PJ (1980) Sexual dimorphism in the body size of Mustelids (Carnivora): the roles of food habits and breeding systems. Oikos 34:147-158

Patton JL, Smith MF (1994) Paraphyly, polyphyly, and the nature of species boundaries in pocket gophers (genus Thomomys). Syst Biol 43:11-26

Pertoldi C, Loeschcke V, Bo Madsen A, Randi E (1997) Developmental stability in the Eurasian otter (Lutra lutra) in Denmark. Ann Zool Fenn 34:187-196

Pertoldi C, Bo Madsen A, Randi E, Braun A, Loeschcke V (1998) Variation of skull morphometry of Eurasian otters (Lutra lutra) in Denmark and Germany. Ann Zool Fenn 35:87-94

Pertoldi C, Loeschcke V, Braun A, Bo Madsen A, Randi E (2000) Craniometrical variability and developmental stability. Two useful tools for assessing the population viability of Eurasian otter (Lutra lutra) population in Europe. Biol J Linn Soc 70:309-323

Pertoldi C, Sonne C, Wiig Ø, Baagøe HJ, Loeschcke V, Bechshøft TØ (2012) East Greenland and Barents Sea polar bears (Ursus maritimus): adaptive variation between two populations using skull morphometrics as an indicator of environmental and genetic differences. Hereditas 149:99-107

Pickles RSA, Groombridge JJ, Zambrana-Rojas VD, Van Damme P, Gotelli D, Kundu $S$ et al (2011) Evolutionary history and identification of conservation units in the giant otter Pteronura brasiliensis. Mol Phylogenet Evol 61:616-627

Platt GS, Rainwater RT (2011) Predation by Neotropical otter (Lontra longicaudis) on turtles in Belize. IUCN Otter Specialist Group Bulletin 28(1):4-10

Platz S, Hertwig ST, Jetschke G, Krüger M, Fischer M (2011) Comparative morphometric study of the Slovakian wildcat population (Felis silvestris silvestris): evidence for a low rate of introgression? Mamm Biol 76:222-233

Pohle H (1920) Die Unterfamilie der Lutrinae. Eine systematisch tiergeographische studie an dem Material der Berliner Messen Archiv für Naturgeschichte 85:1-247
Ricklefs RE, Miles DB (1994) Ecological and evolutionary inferences from morphology: An ecological perspective. In: Wainwright PC, Reilly SM (eds) Ecological morphology: Integrative organismal biology. University of Chicago Press, USA

Rohlf FJ (1996) Morphometric spaces, shape components, and the effects of linear transformations. In: Marcus LE, Corti M, Loy A, Naylor G, Slice DE (eds) Advances in morphometrics. Plenum Publishing Corporation, New York, pp 117-129

Rohlf FJ (2001) TPSdig, version 1.23. State University at Stony Brook, New York, software Rohlf FJ, Marcus LF (1993) A revolution in morphometrics. Trends Ecol Evol 8:129-132

Rohlf FJ, Slice D (1990) Extensions of the Procrustes method for the optimal superimposition of landmarks. Syst Zool 39:40-59

Ruiz-Olmo J, Delibes M, Zapata SC (1998) External morphometry, demography and mortality of the Otter Lutra lutra (Linneo, 1758) in the Iberian Peninsula. Galemys 10:239-251

Sandell M (1996) The mating tactics and spacing patterns of solitary carnivores. In: Gittleman JL (ed) Carnivore behavior, ecology, and evolution. Cornell University Press, Ithaca, New York, pp 164-182

Sheets HD (2002) Semiland6. A tool for processing semi-landmarks. Physics Department, Canisius College, Buffalo, New York, http://www.canisius.edu/ s sheets/morphsoft.html

Sheets HD (2003). MakeFan6 [Online]. Available from http://www3.canisius.edu/ sheets/.

Sheets H D (2005a). CoordGen6, Coordinate Generation program for calculating shape coordinates. http://www3.canisius.edu/ sheets/morphsoft.html.

Sheets H D (2005b). CVAGen6, Canonical Variates Analysis program for the analysis of shape, based on partial warp scores. http://www3.canisius.edu/ sheets/ morphsoft.html.

Sheets HD, Zeldich ML (2001) Tmorphgen6traditional morphometrics variables generation utility part of IMPIntegrated Morphometrics Package. Physics Department, Canisius College, Buffalo, New York, http://www.canisius.edu/ sheets/ morphsoft.html

Smith HM, Chiszar D, Montanucci RR (1997) Subspecies and classification. Herpetological Review 28:13-16

StatSoft (2007) STATISTICA (data analysis software system). StatSoft, Inc, Tulsa, Oklahoma

Thom MD, Harrington LA, MacDonald DW (2004) Why are American mink sexually dimorphic? A role for niche separation. Oikos 105:522-535

Trinca CS, Thoisy B, Rosas F, Waldemarin HF, Koepfli KP, Vianna J et al (2012) Phylogeography and demographic history of the Neotropical otter (Lontra longicaudis). J Hered 103(4):479-492

Van Zyll CG (1972) A systematic review of the Nearctic and Neotropical river otters (Genus Lutra, Mustelidae, Carnivora). Royal Ontario Museum Life Sciences Contributions 80:112

Zelditch ML, Swidwerski DL, Sheets HD (2004) Geometric morphometrics for biologists: a primer. Academic Press of Elsevier, Second edition

\section{Submit your manuscript to a SpringerOpen ${ }^{\circ}$ journal and benefit from:}

- Convenient online submission

- Rigorous peer review

- Immediate publication on acceptance

- Open access: articles freely available online

- High visibility within the field

- Retaining the copyright to your article

Submit your next manuscript at $>$ springeropen.com 